\title{
تكنولوجيا المعلومات وأثرها في نشأة الأطفال في المجتمع العربي
}

\author{
إlula
}

\section{د. رانده أحمد عثمان نديم \\ Doi: 10.12816/jacc.2020.73409}
r. r./ r / rV : القبول

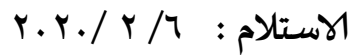

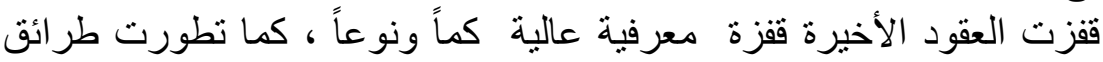

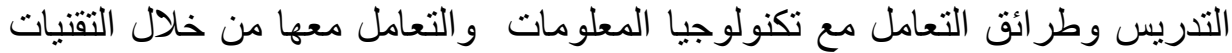

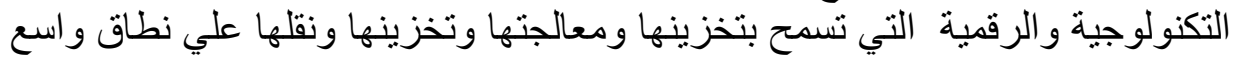

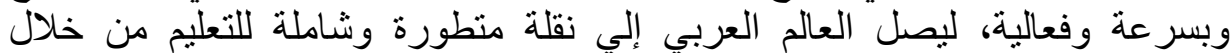

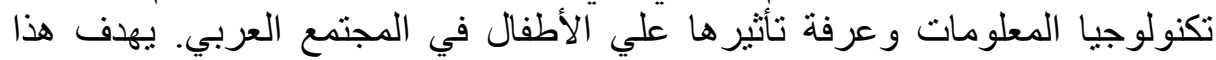

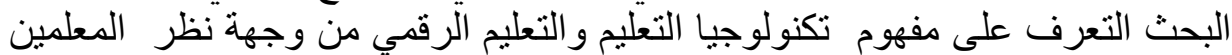

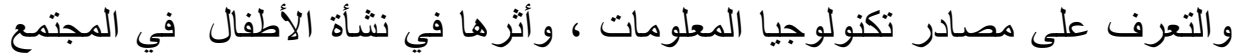

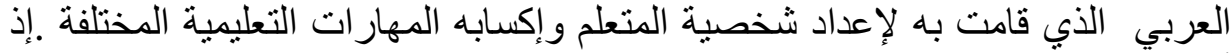

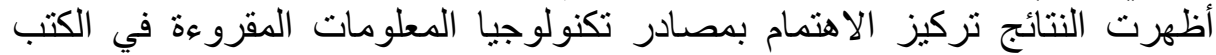

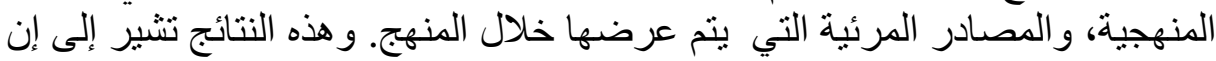

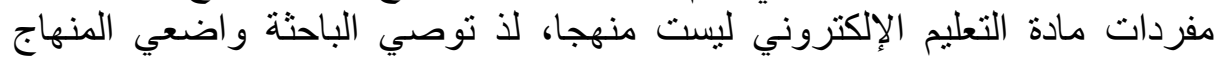

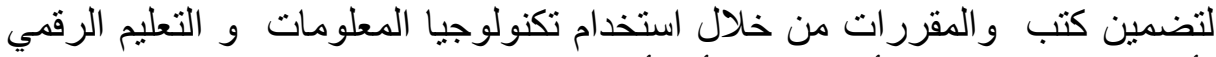
بأنشطة تتعلق بالتربية وأثر ها في نشأة الأطفال في المجنما الثنع العربي. الإطار المنهجي لتهني أولا " مشكلة البحمث: تمحورت مشكلة الدراسة حول التعرف علي تكنولوجيا المعلومات وأثرها في نشأة الأطفال في المجتمع العربي. أهداف البحث: سعت هذه الار اسة علي تحقيق الأهداف التالية:

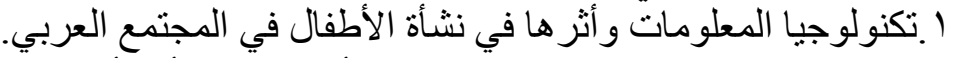

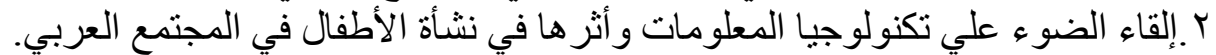

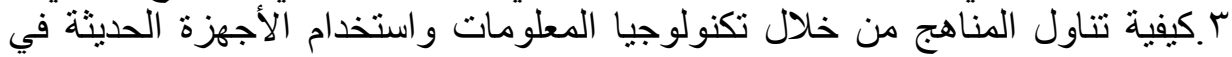

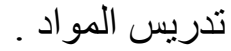


ع كيفية تتاول مناهج التعليم في المجتمع العربي و السودان نموذجا.

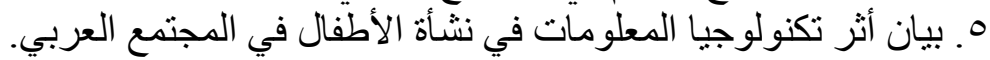

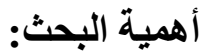

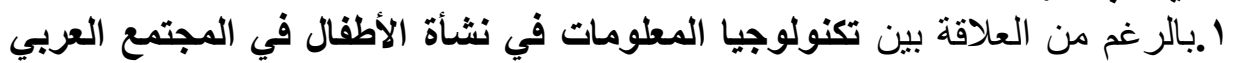

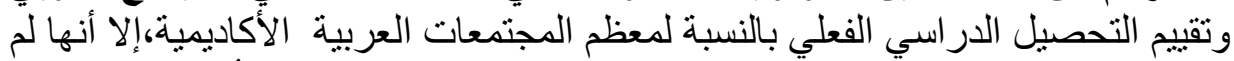

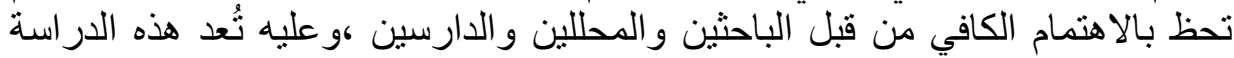

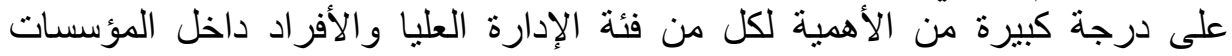

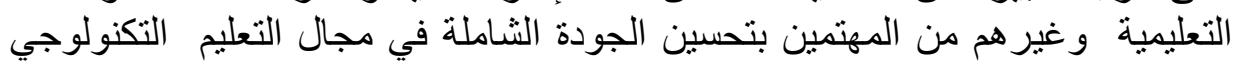

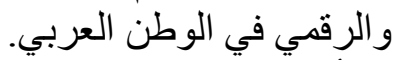
إلا أنها لم تحظ بـ بالان هتمام الكافي من قبل الباحثين و المحللين و الدارسين ،و عليه تُعد هذه

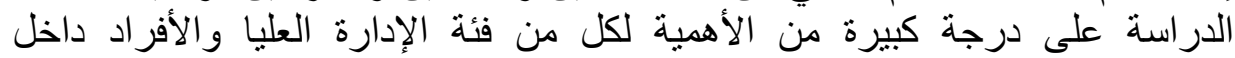

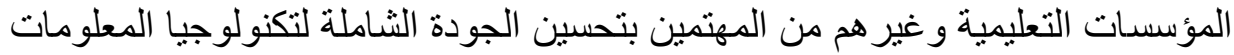

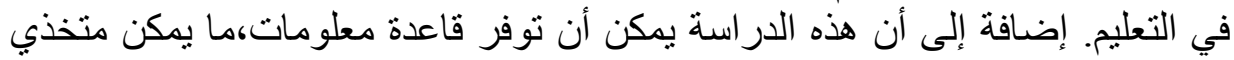

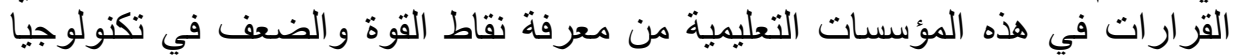

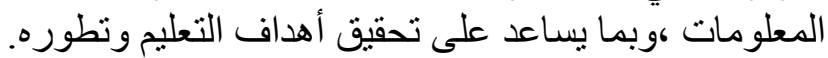

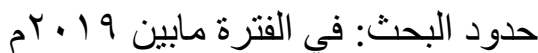
مجتمع البحث و عينته: تلاميذ مرحلة التعليم الأساسي و الإعدادية في الوطن العربي.

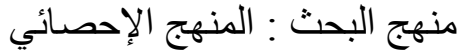

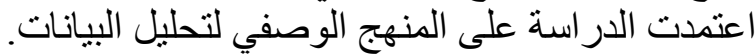
الإطار النظري : مفهوم تكنولوجيا المعلومات الورلئ وأثرهات في نشأة الأطفال في المجتمع العربي

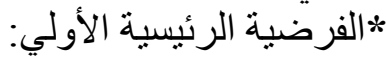
هناك علاقة بين(تكنولوجيا المعلومات وأثرها في نشأة الأطفال في المجتمع العربي). الفرضيات الفر عية:ا - هناك علاقة بين الأجهزة ونشأة الأطفال في المجتمع العربي.

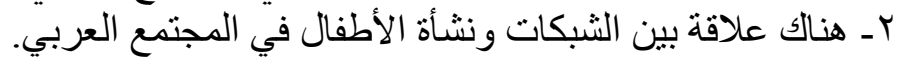

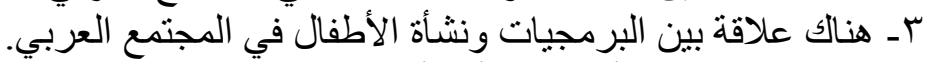

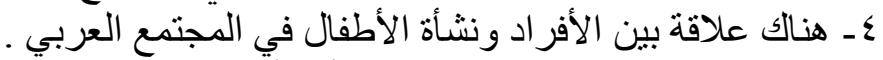

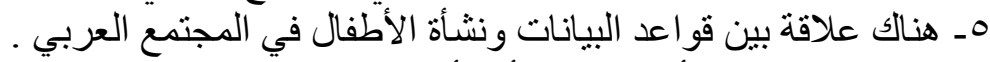

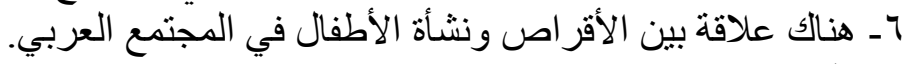
مصطلحات البحث: 1. تعريف تكنولوجيا المعلومات: 
تكنولوجيا المعلومات أو تقنية المعلومات عبارة عن اختصاص و اسع بهنم بجميع نواحي

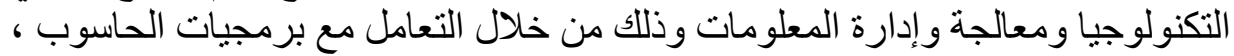
والحواسيب الإلكترونية بهدف تحويل وتخزيل والتين وحماية ومعالجة ونقل واستعادة

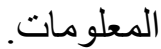

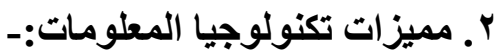

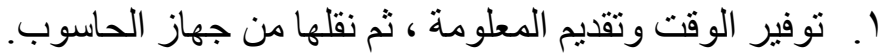

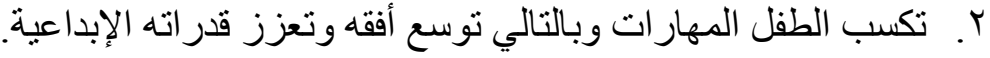

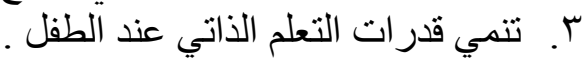
ع. تمنح الطفل الثعور بالراحة الثة عند جمع المعلومات ،حيث أنها تقنية مرتبة ومنظمة وغير عشو ائية. •. تتمي لدي الطفل أسلوب حل المشكلات التي لا يمكن حلها بالطرق التقليدية بسبب

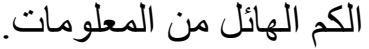

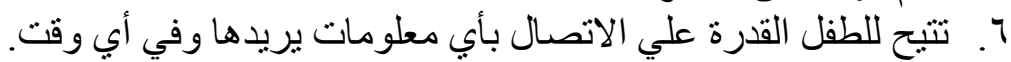

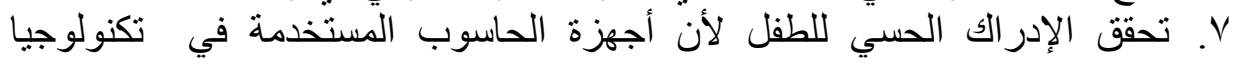

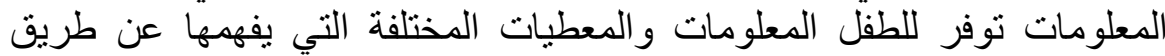
حواسه.

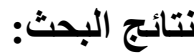

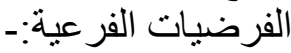
ا - هناك علاقة بين الأجهزة ونشأة الأطفال في المجتمع العربي.

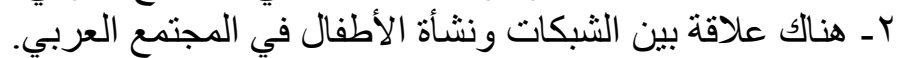

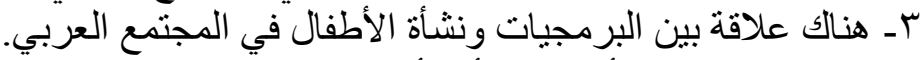

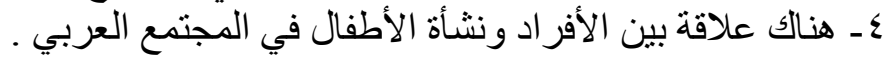

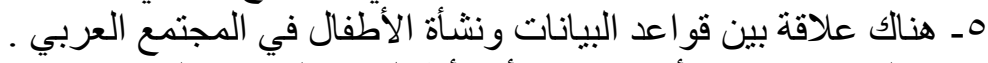

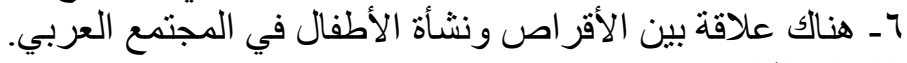

الفصل الثالث إجراعات الدراسة الميدانية

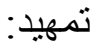
يتم في هذا الفصل إجراءات الدراسة الميدانية.

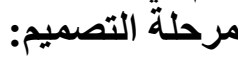

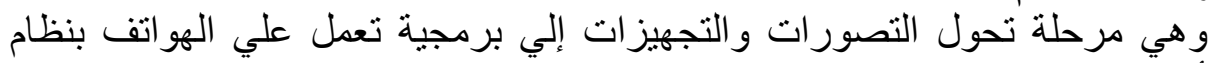

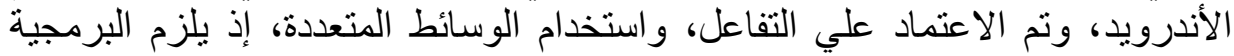

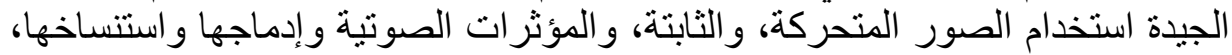

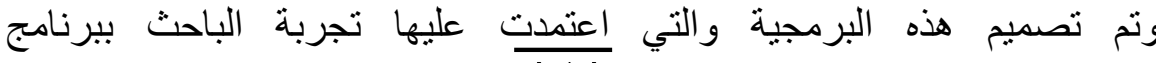


وهو من أفضل و أسهل البر امج لإنشاء الدروس التعليمية الالكترونية (ActivInspire)

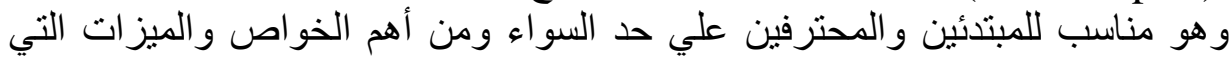
يتمتع بها: أـ يدعم اللغات المكتوبة من اليمين إلي اليسار، و هذا يجعله من البرامج المثالية لإنثاء الدروس باللغة العربية.

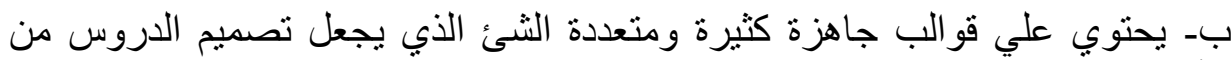

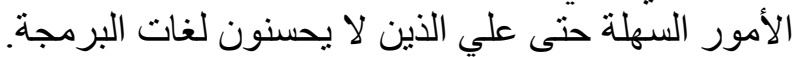

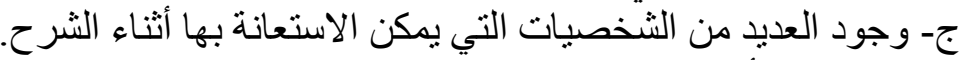
د- يمكن من أخذ الفيديوهات من البرنامج بصورة مباشرة دون الأنة الحاجة إلي برامج الثرج

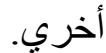
هـ يتمتع بخاصية السحب و الإفلات. و - يمكن من تصوير سطح المكتب مما يجعل من السهل أخذ صور لما تريد للتنلاميذ أن يفعلوه مباشرة. ز- وجود إمكانية إنشاء الأسئلة والأجوبة أثناء الدرس يجعل عملية التقويم سهلة ومستمرة.

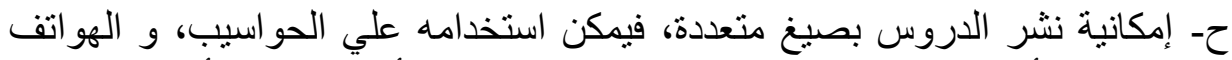
علي اختلاف أنظمة التشغيل التي تعمل بها، ومن بين فين هذه التهن الأنظمة نظام الأندرويد.

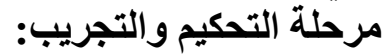
في هذه المرحلة تم عرض البرمجية علي علي عدد من المحكمين من الخبراء التربويون

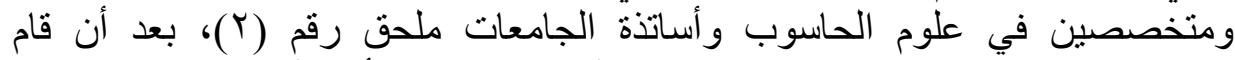

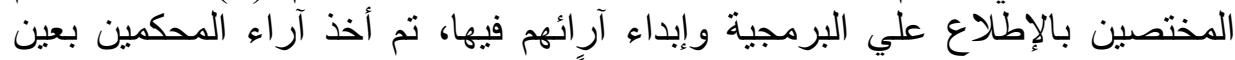

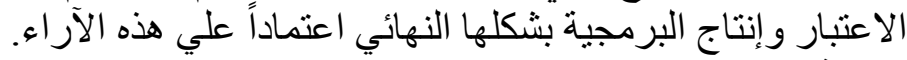

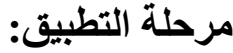

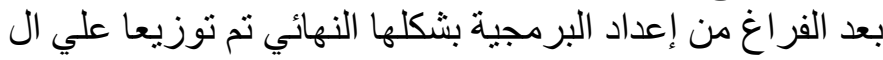

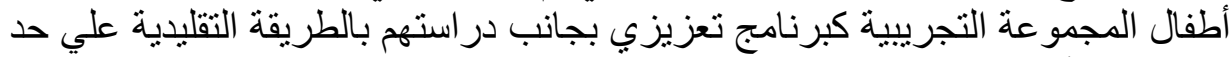

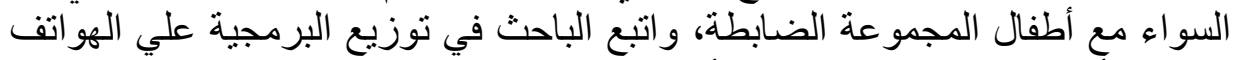

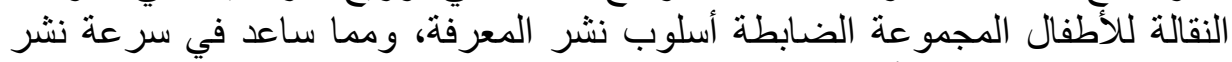

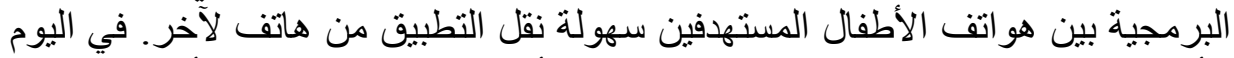

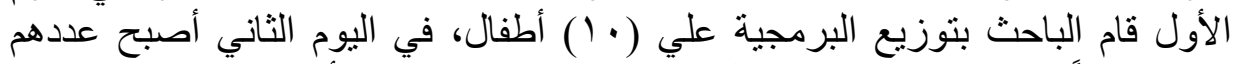

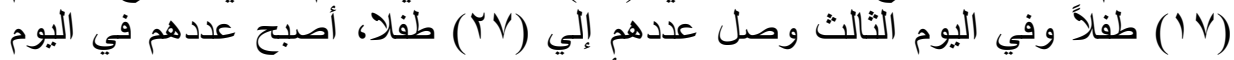
الر ابع (q⿳)، في اليوم الخامس كان عدد الأطفال الذين يحملون البرمجية علي هو اتفهم 
(0) طفلا، يمثلون المجموعة التجريبية من عينة البحث، وطبقت الباحثة أسلوب نشر أبراء

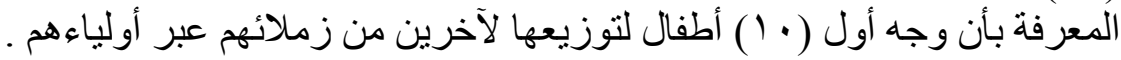

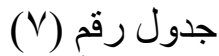
يوضح الأطفال الذين نقلت إليهم البرمجية إلي هو اتفهم و نسبة زيادتهم حسب الأيام

\begin{tabular}{|c|c|c|}
\hline النسبة & عدد الأطفال & الأيام \\
\hline$\%$ r. & 1 & اليوم الأول \\
\hline$\% \Gamma \varepsilon$ & IV & اليوم الثاني \\
\hline$\% 0 \leq$ & TV & اليوم الثالت \\
\hline$\% \vee \wedge$ & rq & اليوم الر ابع \\
\hline$\% 1 \ldots$ & 0 . & ليوم الخامس \\
\hline
\end{tabular}

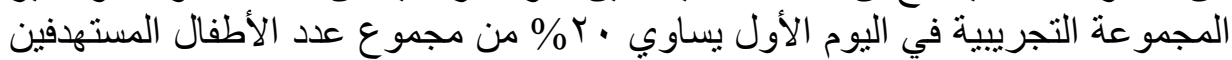

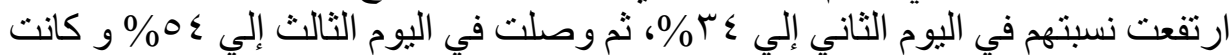

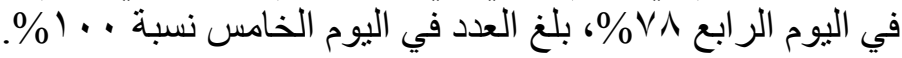
بـ9 المعالجة الإحصائية:

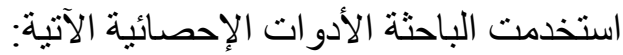

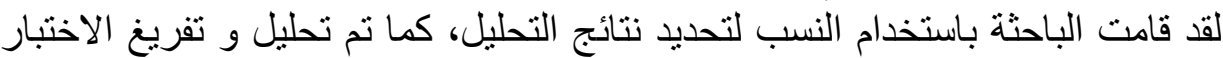
من خلال برنامج (SPSS) للتحليل الإحصائي وتم استخدام الاختبارات الإحصائية التالية: أـ النسب المئوية و التكر ارات. بـ المتوسط الحسابي والانحر اف الت المعياري.

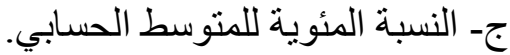
د- اختبار ات (ت) لعينتين مستقلتين. توجد عدد من القو انين و المعادلات منين منها: '

$$
\begin{aligned}
& \text { اختبار ت ت ت } \\
& \text { ت } \\
& \text { ن }
\end{aligned}
$$

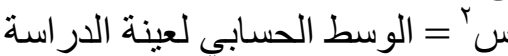

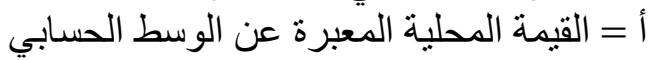
ع = الانحر اف المعياري المعة المعير

ـ محمد عبيدات وآخرون - منهجية البحث العلمي-ـدار وائل للطباعة و النشر - طب ـ الاردن - 999 ام - 


$$
\begin{aligned}
& \text { ن = حجم العينة } \\
& \text { المتوسط الحسابي = مج (مركز الفئة × التكر ار) } \\
& \text { حيث ن هي عدد أفراد العينة } \\
& \text { الانحر اف المعياري= }
\end{aligned}
$$

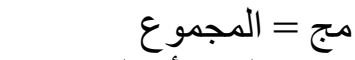

$$
\begin{aligned}
& \text { س = القيمة أو المفردات } \\
& \text { س ب = الوسط الحسابي } \\
& \text { ن = عدد المفردات }
\end{aligned}
$$

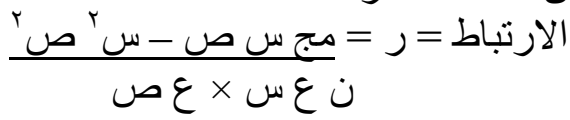

$$
\begin{aligned}
& \text { ر = ارتباط بيرسون } \\
& \text { س = المتغير الأول } \\
& \text { ص = المتغير الثاني } \\
& \text { س = الوسط الحسابي للمتغير الاول } \\
& \text { ص ع = الوسط الحسابي للمتغير الثناني }
\end{aligned}
$$

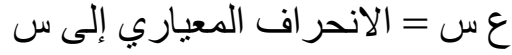

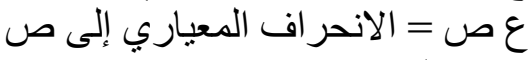

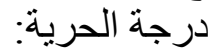

$$
\begin{aligned}
& \text { مفهوم إحصائي يشر إلى عدد الدرجات التي لها حرية تميز }
\end{aligned}
$$

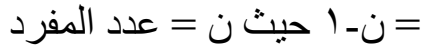

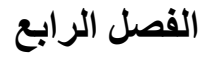

$$
\begin{aligned}
& \text { عرض وتحليل ومناقشة النتائج } \\
& \text { عـ ا } 1 \text { مقدمة: }
\end{aligned}
$$

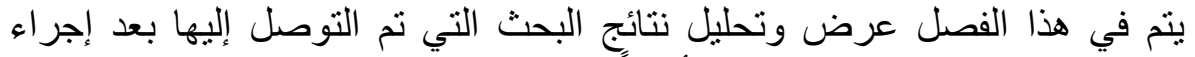

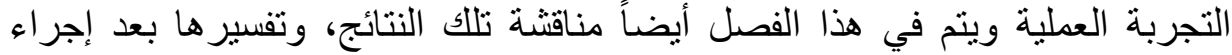
التحليل للنتائج.

$$
\text { و أتقسم نتائج البحث إلب قسمين: }
$$

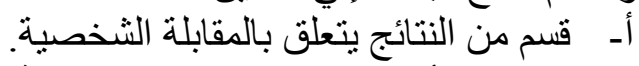
المبحث الأول: تحليل البيانات الثختية بالثة: 


\begin{tabular}{|c|c|c|}
\hline النسبة\%\% & التكر ارات & النوع \\
\hline$\% 0$ & 0 & ا. ذ ذكر \\
\hline$\% 0$. & 0. & Y. أنتي \\
\hline$\% 1 \ldots$ & $1 \ldots$ & المجموع \\
\hline
\end{tabular}

بـ التجربة العملية.

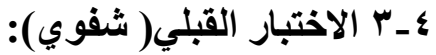

\begin{tabular}{|c|c|c|c|c|c|c|c|c|}
\hline & & & & & & & \multicolumn{2}{|c|}{ جدول رقم (1) } \\
\hline الدالة ل & الحربة & \multicolumn{2}{|c|}{ درجة الثقة95\% } & الارتباط & الانحر اف & المتوسط & العدد العد & \\
\hline 0.06 & 49 & 1.079 & .001 & .972 & 8.132 & 15.50 & 50 & التجرييية \\
\hline 0.06 & 49 & 1.079 & .001 & .972 & 7.969 & 14.96 & 50 & الضـابطة \\
\hline
\end{tabular}

بالنظر إلي الجدول رقم () في الامتحان القبلي، وكان عدد أطفال المو هبة والتميز فيه

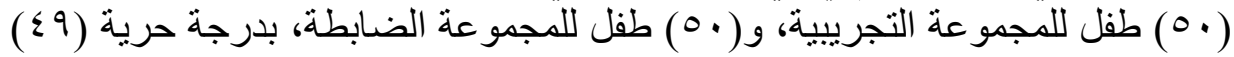

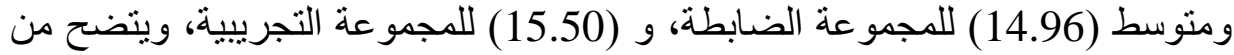

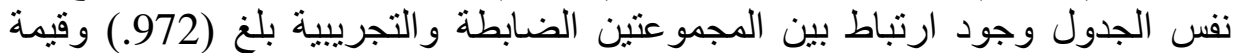

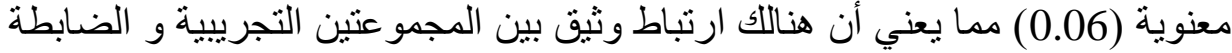

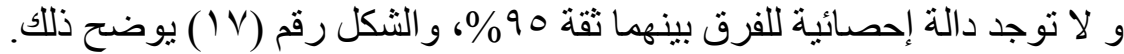
شكل رقم (IV) رسم بياني يوضح الدالة الإحصائية للفرق بين المجموعة التجريبية و الضابطة

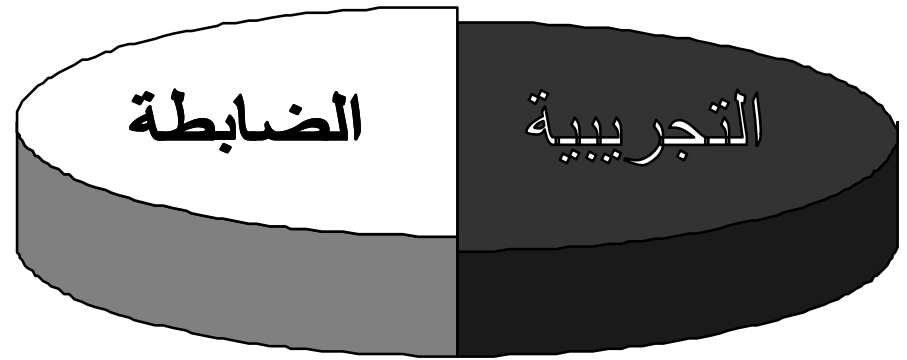

ع ــ الاختبار البعدي:

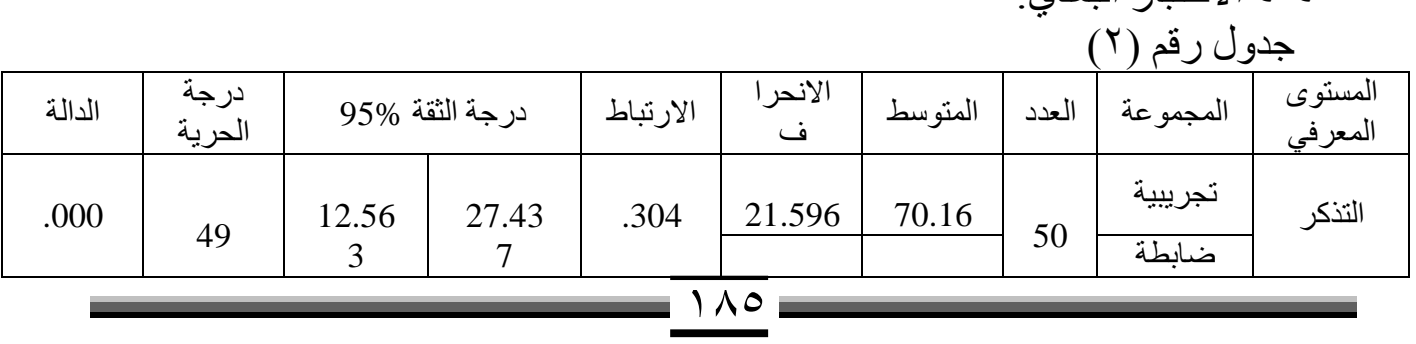


Doi: 10.12816/jacc.2020.73409

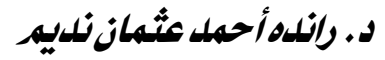

\begin{tabular}{|c|c|c|c|c|c|c|c|c|c|}
\hline & & & & & 22.753 & 50.16 & & & \\
\hline \multirow[b]{2}{*}{.000} & \multirow[b]{2}{*}{49} & \multirow{2}{*}{$\begin{array}{c}24.78 \\
6\end{array}$} & \multirow{2}{*}{8.094} & \multirow{2}{*}{.015} & 28.146 & 40.92 & \multirow[b]{2}{*}{50} & تجريبية & \multirow{2}{*}{ الفهخ } \\
\hline & & & & & 8.820 & 57.36 & & ضابطة & \\
\hline \multirow{2}{*}{.063} & \multirow{2}{*}{49} & \multirow{2}{*}{$\begin{array}{c}19.00 \\
5\end{array}$} & \multirow{2}{*}{$-.525-$} & \multirow{2}{*}{.101} & 28.146 & 40.92 & \multirow{2}{*}{50} & تجرييية & \multirow{2}{*}{ التحليل } \\
\hline & & & & & 22.753 & 50.16 & & ضابطة & \\
\hline \multirow[b]{2}{*}{.000} & \multirow[b]{2}{*}{49} & \multirow{2}{*}{$\begin{array}{c}19.00 \\
5\end{array}$} & \multirow[b]{2}{*}{$-.525-$} & \multirow[b]{2}{*}{.101} & 28.146 & 40.92 & \multirow[b]{2}{*}{50} & تجرييية & \multirow{2}{*}{ التطبيق } \\
\hline & & & & & 22.753 & 50.16 & & ضابطة & \\
\hline \multirow[b]{2}{*}{.000} & \multirow{2}{*}{49} & \multirow{2}{*}{$\begin{array}{c}19.00 \\
5\end{array}$} & \multirow[b]{2}{*}{$-.525-$} & \multirow[b]{2}{*}{.101} & 28.146 & 40.92 & \multirow[b]{2}{*}{50} & تجريبية & \multirow{2}{*}{ التحصيل } \\
\hline & & & & & 22.753 & 50.16 & & ضابطة & \\
\hline
\end{tabular}

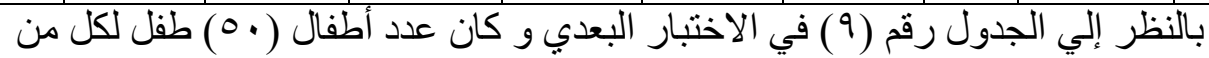

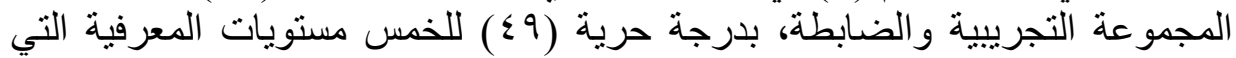

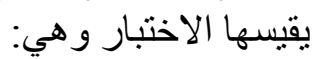

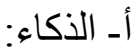

من الجدول رقم (9) نجد أن المتوسط للمجموعة التجريبية (70.16)، و و(50.16)

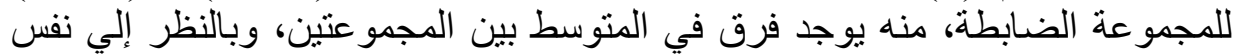

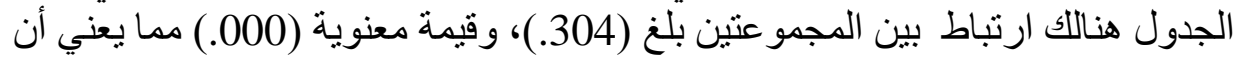

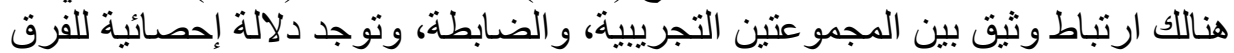

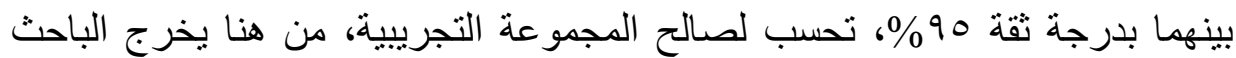

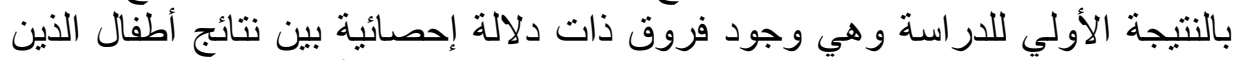

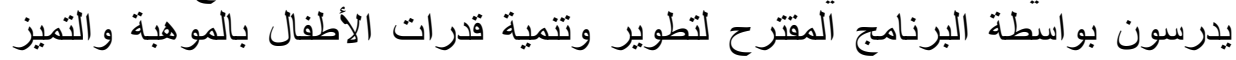

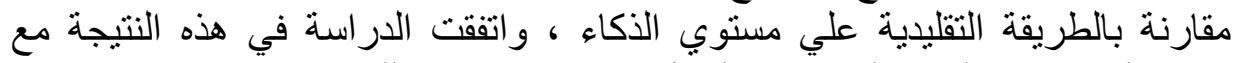

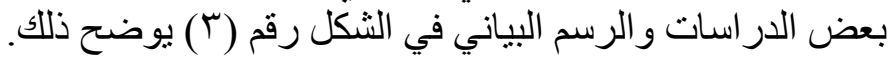

شكل رقم (ب) بان رسم بياني يوضح الدلالة الإحصائية للفرق بين المجمو عتين عند مستوى الذكاء 


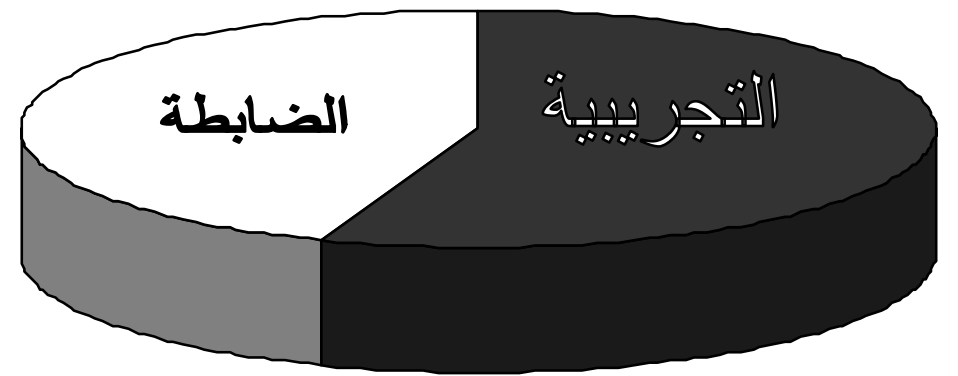

من الجدول رقم (9) نجد أن المتوسط للمجموعة التجريبية (40.92) و(57.36)

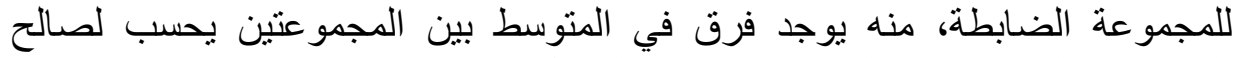

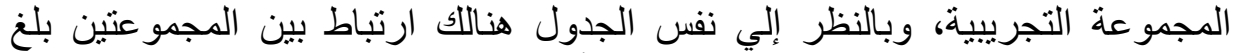

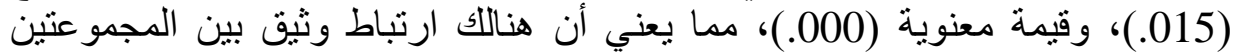

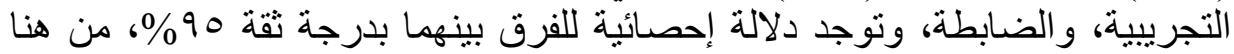

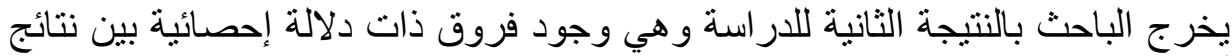

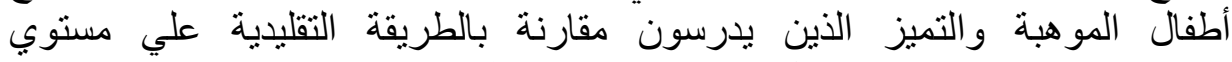
الإبداع،و الرسم البياني في الثكل رقم (9 النميز (19) يوضح ذللك.

شكل رقم (ع )

رسم بياني يوضح الدلالة الإحصائية للفرق بين المجمو عتين عند مستوى الإبداع.

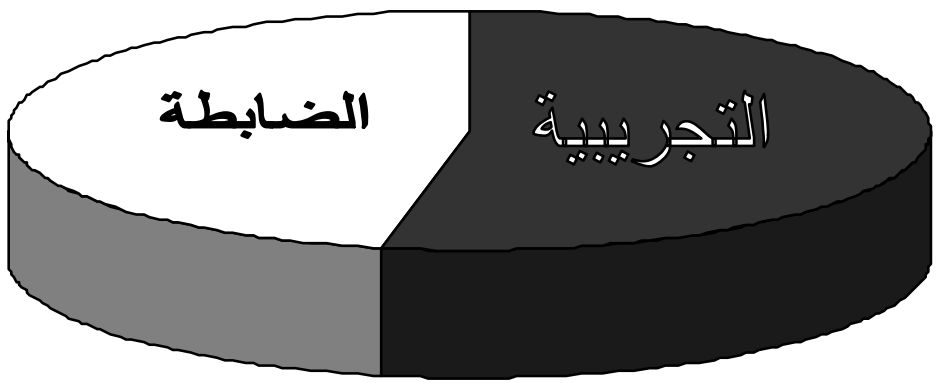

\begin{tabular}{|c|c|c|c|c|}
\hline متوسط الخطأ القياسي & الانحر اف المعياري & العدد & المتوسط & المجمو عة \\
\hline $1 . r_{0}$ & r.or & $\Lambda$ & r. YO & التجريبية \\
\hline $1 . r 0$ & r.or & $\wedge$ & Tr.Vo & الضابطة \\
\hline
\end{tabular}


جدول(ت) رقم (0)

\begin{tabular}{|c|c|c|c|c|c|c|c|c|}
\hline \multirow[b]{2}{*}{ الدلالة } & \multirow{2}{*}{ الحربة } & \multirow[b]{2}{*}{ قتيمة } & \multicolumn{2}{|c|}{ درجة ثقة 90\% } & \multirow{2}{*}{ القوسأ } & \multirow[b]{2}{*}{ المعياري } & \multirow[b]{2}{*}{ الدتوسط } & \multirow[b]{2}{*}{ الدجمو عتين } \\
\hline & & & الادني & الاعلي & & & & \\
\hline TrY. & v & I.r & 1.97 & 7.79 & 1.11 & $0 . \Gamma \varepsilon$ & r.o. & التجريطية + \\
\hline
\end{tabular}

الرسم البياني رقم (r) يوضح الفروق الاحصائية لمستوي الابداع.

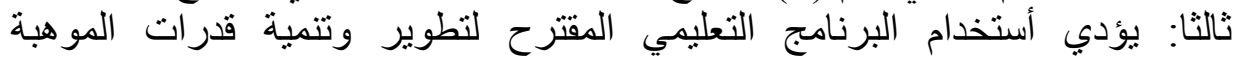

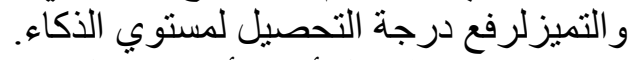

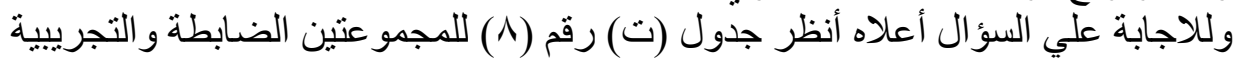

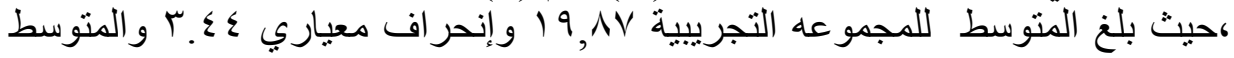

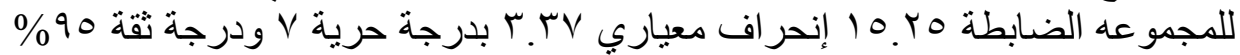

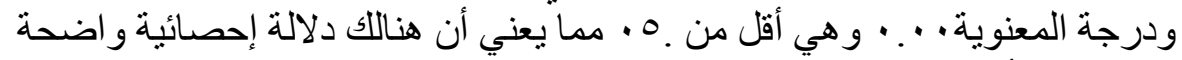

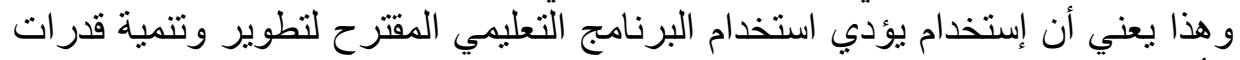

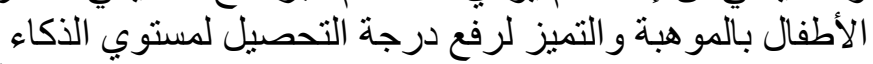

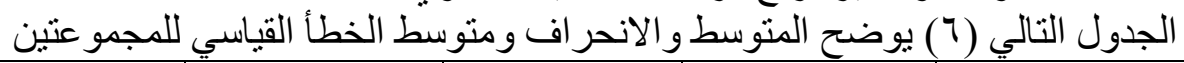

\begin{tabular}{|c|c|c|c|c|}
\hline متوسط الخطاً & الانحرياف & العدد & المتوسط & المجمو عة \\
\hline 1.41 & $r . \varepsilon \varepsilon$ & $\Lambda$ & $19 . \wedge \mathrm{V}$ & التجرييية \\
\hline 1.19 & 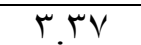 & $\Lambda$ & 10.10 & الضابطة \\
\hline
\end{tabular}

جدول(ت) رقم) (V)

\begin{tabular}{|c|c|c|c|c|c|c|c|c|}
\hline \multirow[b]{2}{*}{ الدلالة } & \multirow{2}{*}{ الحرية } & \multirow[b]{2}{*}{ 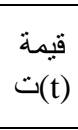 } & \multicolumn{2}{|c|}{ درجة ثقة 90\% } & \multirow{2}{*}{ متوسطاً } & \multirow[b]{2}{*}{ الانحر اف } & \multirow[b]{2}{*}{ المتوسط } & \multirow[b]{2}{*}{ المجمو عتين } \\
\hline & & & الادني & الاعلي & & & & \\
\hline. .10 & v & T.Y & $1 . r r$ & $\Lambda . \cdot r$ & $1 . \leqslant r$ & $\varepsilon . .7$ & $\varepsilon . Y$ & التجريبية \\
\hline
\end{tabular}

1.الفرضية الأولي:هناك علاقة بين الأجهزة ونشأة الأطفال في المجتمع العربي.

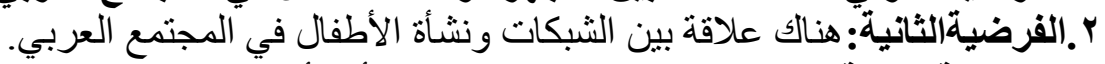

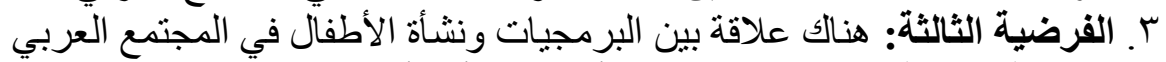

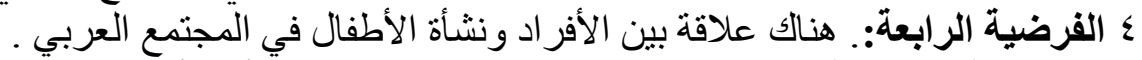

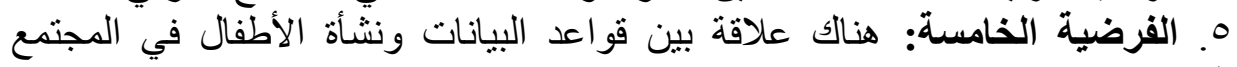
الـ الفرضية السرادسة: هنالك علاقة بين الأقر اص ونشأة الأطفال في المجتمع العربي. 


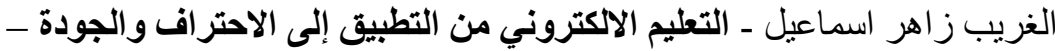

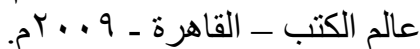

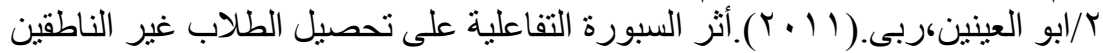
$/$

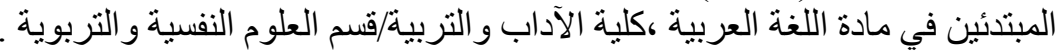

الغريب زاهر اسماعيل ـ تكنولوجيا المعلومات وتحديث التعليم - عالم الكتبـ-

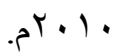

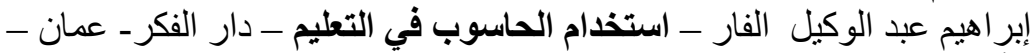

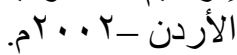

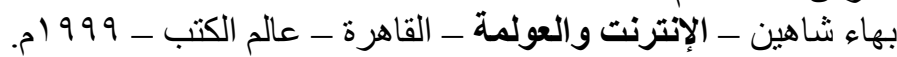
$-0$

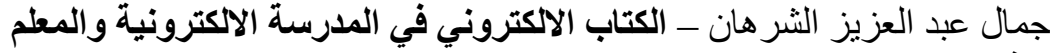

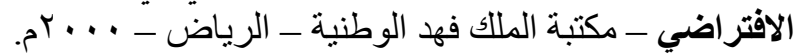

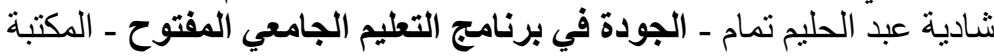

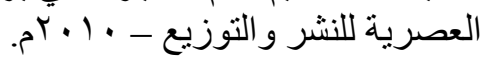

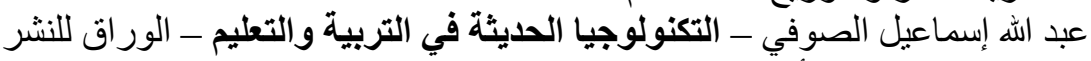

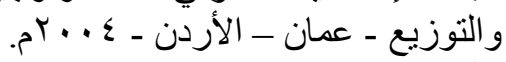

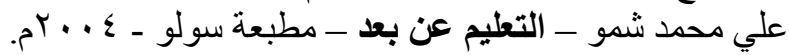
$-8$

غسان يوسف غطيط ـ الحاسوب وطرق التدريس والتقويم ـ دار الثقافة - عمان -

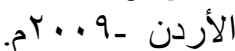

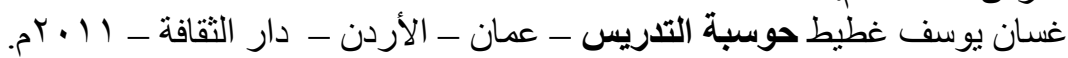

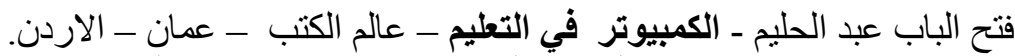
فدوى إحسان الله عمر ـ التقنية الحديثة في إدارة المدارئ المدارس الثانوية للبنات ـ المدينة

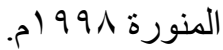

فهيمي مصطفي - مدرسة المستقبل ومجالات التعلم عن بعد - دار الفكر العربي -

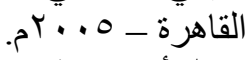

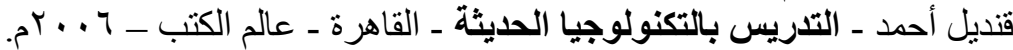

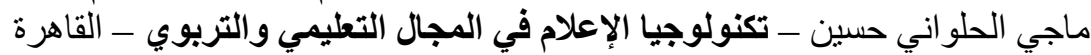

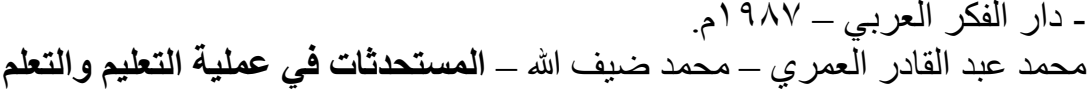
- عالم الكتب الحديث - عمان - الأردن. 
